\title{
Characterising the fracture toughness of polymers at moderately high rates of loading with the use of instrumented tensile impact testing
}

\author{
H.A. Visser ${ }^{* a b}$, F. Caimmi ${ }^{a}$, A. Pavan ${ }^{a}$ \\ aPolitecnico di Milano, Dipartimento di Chimica, Materiali e Ingegneria Chimica “Giulio Natta”, P.za Leonardo \\ da Vinci, 32, I-20133 Milano, Italy \\ ${ }^{b}$ University of Twente, Faculty of Engineering Technology, Production Technology Group, Drienerlolaan 5, 7522 \\ NB Enschede, the Netherlands \\ *Corresponding author: h.a.visser@ctw.utwente.nl, +31 534894061 \\ Keywords: fracture toughness; tensile impact; DE(T); PMMA; PVC; PE; fracture mechanics
}

\section{Abstract}

The more common use of instrumentation in impact testing opened up the possibility to apply fracture mechanics testing methods to polymers at moderately high impact rates. Tensile impact testing offers some advantages over the more common three-point bending and compact tension geometries. Most importantly the dynamic effects encountered at (moderately) high impact rates are less significant due to inherent damping within the specimens. Consequently, the fracture toughness can be determined directly from the force signal without having to employ more sophisticated instrumentation or more elaborate analysis. Despite some unresolved issues the first results on fracture mechanics based tensile impact testing are promising: the toughness values found are comparable to those found using other loading geometries and show less scatter.

\section{Highlights}

- The potential of instrumented tensile impact fracture testing was assessed

- Up to $3.7 \mathrm{~m} / \mathrm{s}$ it allows for $K_{1 c}$ determination directly from load

- Toughness values are comparable to those found using conventional geometries

- Extension to even higher testing rates is open to further investigation 


\section{Nomenclature}

a Initial notch length

$b \quad$ Fitting parameter in eq. (1)

$B \quad$ Specimen thickness

$C_{d} \quad$ Dilatational wave speed

E Tensile modulus

$F(t) \quad$ Fit of the experimental load-time trace according to ISO 17281 [5]

$F_{Q} \quad$ Load at initiation of the crack growth

$K_{I C} \quad$ Fracture toughness (critical stress intensity factor)

$K_{Q} \quad$ Provisional fracture toughness

$m \quad$ Fitting parameter in eq. (1)

$n \quad$ Fitting parameter in eq. (1)

$t \quad$ Time

$t_{0} \quad$ Fitting parameter in eq. (1)

$Y \quad$ Geometrical factor (a function of notch length and specimen width)

$w \quad$ Half of the width of a $D E(T)$ specimen

W Specimen width

Greek symbols

$v \quad$ Poisson's ratio

$\rho \quad$ Density

\section{Introduction}

The development of force acquisition instrumentation for impact tests made it possible to determine fracture mechanics based properties of materials at impact rates [1,2]. The more common use of these instrumented impact tests on polymers has resulted in ISO 17281 [3-5], a standard describing a procedure to determine the fracture toughness of polymers following fracture mechanics and using instrumentation which nowadays is commonplace. Traditional as well as fracture mechanics based impact tests are mostly carried out in bending geometries, such as Charpy, Izod, three-point bending $(\mathrm{SE}(\mathrm{B}))$ and compact tension $(\mathrm{C}(\mathrm{T}))$. Compared to the amount of published research on these bending 
impact geometries, reports on instrumented tensile impact loading are hardly found in literature [6]. This is a remarkable observation considering the (possible) advantages of the tensile loading geometry. Firstly, the distance between the impact point and the notch can be largely varied at will. Secondly, during impact tests in the bending geometries the force is measured at the striker (upstream of the notch) in most cases. At impact the force fluctuations are most severe due to the contact stiffness and inertia effects (causing for example loss of contact). The force measured at the striker, can therefore differ significantly from the resulting stress wave which travels through the specimen $[7,8]$. Additional analyses using for example a lumped (mass/spring/dashpot) model $[9,10]$ might therefore be required to translate the measured signal to the stress at the notch. Tensile impact testing easily offers the possibility to measure the force downstream (at the side where the specimen is fixed), which could reduce the problem. For a Charpy-wise or three-point bending setup downstream force measurement would either require force cells at the supports (out of the notch plane) or a construction commonly found in Hopkinson bar type setups [11]. Moreover, loss of contact can occur at the striker and at the supports [7,8,12], complicating the analysis to extract the stress state at the notch for Charpy or three point bending setups. Thirdly, impact tests at increasing impact rates can give rise to a considerable amount of dynamic effects caused by contact and inertia effects, wave propagation etc. These dynamic effects can have the result that fracture parameters cannot be determined directly from the measured force signal, even if damping is applied at the point of impact. This problem can be circumvented by reverting to measuring the time-to-fracture instead of the load at fracture initiation and analysing the test results via the Dynamic Key Curve (DKC) method [13-15] for higher impact speeds. This method does, however, have the drawback that the modulus of the material should be known for the applied displacement rate. For bending geometries DKC should already be applied at impact speeds above $1 \mathrm{~m} / \mathrm{s}[13,14,16]$. For tensile impact testing, however, the load signal oscillations brought about by the dynamics of the test are damped by the intrinsic dissipation capacity of the specimen itself. Therefore, the application of mechanical dampers is less critical for viscoelastic materials, such as polymers. Consequently, the fracture parameters can potentially be directly determined from the measured force up to higher impact speeds. How far one can go above $1 \mathrm{~m} / \mathrm{s}$, without or with the help of a mechanical damping device placed at a suitable position, remains to be ascertained.

Aim of the present work is to assess the robustness of fracture mechanics based tensile impact testing using an instrumented impact pendulum. After a verification of the force measurement using a high speed camera and specimens equipped with strain gauges, several instrumental and/or test specimen parameters were individually varied. Three different polymers, with different levels of inherent visco-elastic damping, were tested: poly(methyl methacrylate) (PMMA), poly(vinylchloride) (PVC) and a high-density polyethylene (HDPE). This first assessment of the robustness of instrumented tensile impact testing is concluded by comparing some of the fracture toughness results to values reported in literature by others on similar materials using other loading geometries.

\section{Materials and methods}

\subsection{Materials and specimen preparation}

The three materials used in the present study are: a PMMA cast sheet (Repsol glass from Arkema, France) with a thickness of $2 \pm 0.1 \mathrm{~mm}$, a rigid PVC sheet (produced by Mazzucchelli S.p.A, Italy) with a thickness of $4.6 \pm 0.05 \mathrm{~mm}$ and a $2 \%$ carbon black filled HDPE sheet (produced by Hoechst, Germany) 
with a thickness of $5.05 \pm 0.05 \mathrm{~mm}$. The plates were cut in strips with a diamond saw, then milled to the appropriate width and length. A hole with a diameter of $6 \mathrm{~mm}$ was drilled in the tensile impact specimens for the pendulum impact machine by employing a fixture ensuring correct positioning of the hole. Subsequently, a notch was milled at each (long) side, using a broach like apparatus (CEAST Notchvis) equipped with a replacement blade of a Stanley knife having a tip radius of approximately $3 \mu \mathrm{m}$. No subsequent pre-cracking procedure was applied at the notch tips as the notches are considered as being "sharp" enough for the materials under test. Stop blocks are used to ensure that the notches are perpendicular to the side and oppose each other. The resulting double edge notched $(D E(T))$ specimen geometry is shown in Figure 1. After notching the PMMA and PVC specimens are tempered for 30 minutes at $112{ }^{\circ} \mathrm{C}$ and $92^{\circ} \mathrm{C}$ respectively to remove any residual stresses applied during specimen preparation and to erase any physical ageing history. Strain gauges (steel $120 \Omega$ $0,6 / 120$ LY11 strain gauges by HBM) were glued on some of the specimens to assess the strain during testing.

\subsection{Experimental setup}

All tensile impact tests were carried out on a CEAST impact testing pendulum (6545/000), equipped with a tensile testing fixture (CEAST M 1303 6547.919) and connected to CEAST DAS 8000 data acquisition system, which offers an acquisition frequency of $2 \mathrm{MHz}$. A photograph of the setup used throughout the present study is shown in Figure 2. The specimens are installed with the hole at the side of the fixed crosshead with a bolt that clamps the specimen between two ridged steel plates. Bolt and hinge are expected to allow for minor alignment corrections during experiments. The movable crosshead is attached to the other side of the specimen with two bolts. The torque used to clamp both sides is kept constant using a torque wrench. After some initial testing, the required amount of torque was determined to be $5 \mathrm{Nm}$. On the surfaces where the pendulum hammer strikes the movable crosshead a layer of silicon grease is applied to damp some of the dynamic effects caused by contact stiffness and inertia. The silicon grease layer was applied with a thickness of 0.1 $\mathrm{mm}$ (unless otherwise stated) with the use of an aluminium window frame. The pendulum machine is capable of testing up to impact speeds of $3.7 \mathrm{~m} / \mathrm{s}$.

The quasi-static tests were carried out on a Zwick Z5.0 universal mechanical testing machine equipped with a $2.5 \mathrm{kN}$ load cell.

All tests were carried out at room temperature.

\subsection{Fracture toughness evaluation}

The fracture toughness $\left(K_{I C}\right)$ of the tensile impact specimens was determined from the load at fracture initiation extracted from the measured load-time trace by applying the procedure set out in the ISO 17281 standard [5], to which the reader is referred for details. For the purposes of the present paper it is sufficient to recall that the procedure to identify fracture initiation involves the following steps:

- Fitting the recorded load-time trace to the equation

$$
F(t)=m\left(t-t_{0}\right)-b\left(t-t_{0}\right)^{n},
$$


where $F$ is the load, $t$ is time and $b, n, m$ and $t_{0}$ are fit parameters. This is a smoothing procedure aimed at filtering out oscillations in the load trace to find a "baseline" which, in principle, should be the equivalent of a quasi-static load trace, but at higher loading rate, the effect of dynamics being purged;

- Determining the fracture initiation load $\left(F_{Q}\right)$ by the standard 5\%/Max criterion [17] using the fitted curve instead of the actual load-time trace ;

- Verifying that the original load-time trace, between $F_{Q}$ and $F_{Q} / 2$, is confined in the envelope defined by the two curves $F(t)+0.05 F_{Q}$ and $F(t)-0.05 F_{Q}$. If the experimentally recorded force trace does not fall into this $10 \%$ envelope, oscillations are deemed to be too large for the fit to be an acceptable representation of what the system response would be in the absence of dynamic effects. In that case the method set out by ISO 17281 cannot be applied.

Quasi-static tests results were reduced by applying the procedure given by the relevant ISO standard (ISO 13586 [17]) except for the different test configuration (DE(T) instead of $S E(B)$ or $C(T)$ ). In both the dynamic and the quasi-static case the load at initiation of the crack growth $\left(F_{Q}\right)$ is used to calculate a provisional value of fracture toughness $\left(K_{Q}\right)$ according to:

$$
K_{Q}=\frac{F_{Q}}{B W} Y \sqrt{\pi a}
$$

where $B$ is the thickness of the specimen, $W$ is the width of the specimen, $a$ the initial notch depth and $Y$ a geometrical factor characteristic of the test configuration. For the $\mathrm{DE}(\mathrm{T})$ case an expression provided by Benthem and Koiter as reported by Rooke et al. [18] and valid for $a / w \leq 0.7$ is used here:

$Y=\left[1.12\left(1-0.5 \frac{a}{w}\right)-0.015\left(\frac{a}{w}\right)^{2}+0.091\left(\frac{a}{w}\right)^{3}\right] / \sqrt{1-\frac{a}{w}}$

The $w$ is defined as half of the width of the $D E(T)$ specimen, $W$, as the $D E(T)$ specimen contains two notches.

\section{Results}

\subsection{Stress wave propagation}

Upon impact, the stress wave travels through the specimen, the stress at the notches increases up to the point where the stress intensity at the notch tips reaches its critical value and fracture occurs. In the meantime the stress wave has travelled further and reached the fixed crosshead and force cell. Part of the stress wave will be reflected from this side. It depends on the stress wave propagation speed whether reflection reaches the notched cross-section before or after fracture has occurred at the crack tip. One specimen of each material was equipped with two strain gauges attached on the top part of the specimen: one between the moving crosshead and the notches (upstream) and one between the notches and the fixed crosshead (downstream), as represented in Figure 3 (left). The specimens were tested at an initial impact velocity of $1 \mathrm{~m} / \mathrm{s}$ and with $0.1 \mathrm{~mm}$ of silicon grease placed on the moving crosshead surface where the striker hits the crosshead. The strain gauge signals measured on the PMMA specimen are shown in Figure 3 (left) along with the measured force signal. 
Combining strain gauge and force signals yields an estimate for the modulus of $5.1 \mathrm{GPa}$ for PMMA, of 3.1 GPa for PVC and 1.6 GPa for HDPE, which are in the range of literature data by others [19-22].

The delay of the downstream strain gauge signal when compared with the signal of the one upstream set a distance of about $43 \mathrm{~mm}$ apart is about $18.5 \mu \mathrm{s}$, indicating a stress wave propagation speed of about $2300 \mathrm{~m} / \mathrm{s}$. The dilatational wave speed $\left(C_{d}\right)$ for the plane strain and plane stress situation are given by [23]:

plane strain: $\quad C_{d}=\sqrt{\frac{E(1-v)}{\rho(1+v)(1-2 v)}}$

plane stress: $\quad C_{d}=\sqrt{\frac{E}{\rho\left(1-v^{2}\right)}}$

In these equations $E$ is the tensile modulus, $\rho$ the density $\left(1200 \mathrm{~kg} / \mathrm{m}^{3}\right.$ for PMMA) and $v$ the Poisson's ratio ( 0.34 for PMMA). Using the previously found value for the modulus shows that the measured wave speed is in between the theoretical plane strain $\left(C_{d}=2560 \mathrm{~m} / \mathrm{s}\right)$ and plane stress $\left(C_{d}=2190 \mathrm{~m} / \mathrm{s}\right)$ situations. At this propagation speed the stress wave will travel through the unclamped part of the specimen in about $20 \mu \mathrm{s}$, which is a much shorter time than the 400 to $1000 \mu \mathrm{s}$ testing time (time-tofracture). Hence, during the test the stress wave will travel back and forth along the specimen many times, a situation which is not dissimilar from a quasi-static case.

It can also be observed in Figure 3 (left) that the two strain gauge signals, besides being shifted somewhat apart, are a bit different in magnitude during the loading phase: this might be interpreted as indicative of some bending of the two specimen halves in opposite vertical direction. The behaviour of the two signals after breaking (consider the longer wavelength oscillations indicated by the arrows) would support this interpretation.

Another PMMA specimen was equipped with two strain gauges attached to the top and bottom, as indicated in Figure 3 (right). Again some difference in magnitude between the two strain gauge signals is observed during the test (loading phase): the strain gauge attached to the top gives a larger signal than the one from the one at the bottom, indicating the presence of a strain gradient through the specimen thickness. This suggests that some bending occurs during testing, with the top of the specimen stretched more than the bottom. After fracture, in the absence of any tensional force, the opposite occurs in the half-specimen clamped to the fixed crosshead: the strain gauge attached to its top indicates an oscillating, but fully negative, i.e. compressive, tensile strain. The one at its bottom indicates an oscillating but fully positive tensile strain, and the two oscillate in phase, which would correspond to an opposite flexure.

This bending might be caused by a misalignment of the impact surface of the movable crosshead with respect to the impact surface of the striker on the pendulum. From the difference in the two strain gauge signals at fracture, a maximum bending strain of $0.06 \%$ can be estimated in the unnotched cross-sections of the specimen. Using $E=5.1 \mathrm{GPa}$, a corresponding extra bending stress (positive at the top surface of the specimen and negative at the bottom one, away from the notches) in the order of $3 \mathrm{MPa}$ at fracture can be deduced. This would mean a significant contribution as the 'applied' tensile stresses are in the order of 15 MPa for PMMA at fracture. 
This speculation is perhaps misleading, since if such a bending indeed occurs it should entail the effect of a slant crack front with fracture starting at one end of the crack front (where the bending stress is higher), a fact which has not been generally observed. Nevertheless, a more in depth investigation on the possible occurrence of bending is required in future work.

\subsection{Significance of the force measurement}

It is of crucial importance to pinpoint the force at which the crack growth initiates, in order to determine the fracture resistance of polymers. Unfortunately, under even moderately high impact rates the forces acting on the specimen at the tip of the initial crack can be measured directly only by using techniques rather sophisticated such as caustics [8], digital image correlation [24], etc. which are not readily available to the ordinary laboratory and this would make the method unsuited for a standard usage. Instead the force is recorded more downstream, at the fixed crosshead, here. The stress wave therefore has to travel through part of the specimen and in the fixed clamp before it is measured at the force cell. Hence the measured force may differ from the one actually acting at the crack plane (see e.g. [8]).

An ad hoc experiment was devised to check whether the force measured at the cell, i.e. away from the crack, is nevertheless a good indication of the stress that causes crack initiation. Three specimens with two pairs of notches were tested. The double notch which is encountered first by the stress wave is located at exactly the same position as in the regular $D E(T)$ specimen geometry shown in Figure 1, i.e. midway between the two clamps. The second set of notches was located at $15 \mathrm{~mm}$ distance from the first set, downstream. The force displacement curves of these tests prove to be very similar to the curves measured on regular $D E(T)$ specimens, with only a slight increase of the compliance, as expected. The specimen fractured at the first set of notches encountered by the stress wave and the stress wave propagating beyond that was still of such intensity that a crack was initiated at one of the two notches of the second pair, although it did not propagate all the way through. This occurred in all the three specimens tested. A microscopic image of one of these initiated (and then arrested) cracks at the second set of notches is shown in Figure 4.

\subsection{Check-up of test specimen setting}

A typical result of three impact test replicates is given in Figure 5. It is demonstrated that the load trace during fracturing is quite reproducible. Furthermore, even the post-mortem force fluctuation proves to be very reproducible and not just erratic, as has also been observed for three point bending, $\mathrm{SE}(\mathrm{B})$, impact tests [10]. ${ }^{1}$

Close examination of the fracture surface of impacted specimens reveals that within the short period of impacting a crack grows at both notches of the specimens. In most cases one of the cracks grows more rapidly and the two cracks merge somewhere on the left or right side of the specimen. In some

\footnotetext{
${ }^{1}$ The thickness of the plates from which the specimens were taken out varied somewhat, up to $10 \%$ for PMMA, from plate to plate, which obviously has its effect on the measured force values. In the graphical representation of the recorded force versus time traces the force is therefore normalized with respect to the specimen cross-section area $B W$, i.e. it is reported as engineering stress $(=F /(B W))$ throughout most of this paper.
} 
cases, about one out of five, the merging of the crack fronts does occur just in the centre of the specimen, like the specimen shown in Figure 6. Unlike what would be expected if bending of the specimen contributes significantly to fracture, the cracks do not appear to initiate at the top or bottom of the notches in the specimen. The conical markings indicate that the direction of the crack propagation is mainly horizontal towards the merging [23], the vertical line on the surface, and that these cracks approach from both sides. Where for the other cases the cracks do not merge at the centre, still they do initiate at both sides (as also supported by the visibility of conical markings in both directions). The fact that a crack propagates from both sides indicates a proper alignment of the specimen and proper alignment of the opposing notches of the specimens. The conical markings are a result of secondary micro-crack initiation at some defects ahead of the primary crack, due to the high triaxial tensile stress levels reached ahead of the crack [23]. These micro-cracks tend to be at a different plane as the primary crack, typically in the order of $1 \mu \mathrm{m}$ above or below the primary crack plane. Coalescence of these cracks leaves a conical marking. The fracture surface encountered here contains about 20 markings per $\mathrm{mm}^{2}$, which is a lot lower than the marking density observed by Ravi-Chandar for PMMA [23], but in the same order as observations by Cotterell [25]. Both authors argue that the density of the markings increase with an increase in stress intensity. The same is observed here; the density of markings increases towards the merging of the left and right crack path.

\subsection{Damping}

Tests that are conducted at moderate to high impact speeds are known to show an increasing influence of dynamic effects. Despite the inherent, internal damping effect of the viscoelastic behaviour of the polymeric specimen itself in tensile impact testing, dynamic effects can still occur and can make the data analysis more difficult. Applying some external damping by cushioning the initial contact between the striker and the movable crosshead with a highly viscous material can, however, suppress or reduce to a large extent these dynamic effects, just as in the case of the bending impact testing $[5,6]$. Also in the case of tensile impact testing care should be taken not to exaggerate the amount of external damping as this might alter the impact response of the specimen.

In this study the amount of external damping material applied on the movable crosshead has been varied and its effect was tested at the worst-case scenario: impact tests at maximum initial pendulum speed $(3.7 \mathrm{~m} / \mathrm{s})$. The influence of damping is shown in Figure 7 (left). The effect of the use of a layer of silicon grease of $0.1 \mathrm{~mm}, 0.3 \mathrm{~mm}, 0.6 \mathrm{~mm}$ thickness is compared with the case of a test performed without the use of any external damping material.

It is interesting to observe that, even when no damping is applied externally, the recorded force trace is rather smooth, without substantial fluctuations. Only a hump appears on the raising portion of the loading curve: this is obviously the manifestation of a residual upward fluctuation (above the "true" momentary value of the force, as it would appear in the absence of any dynamic effect), followed by a minor downward fluctuation (below the "true" value of the momentary force, as it would appear in the absence of any dynamic effect). It is worth noting that failure, indicated by the load dropping after its maximum, occurred here while the force signal was in a downward fluctuation: the 'apparent' value of the load at failure is therefore lower than the "true" critical load, in this case. The opposite would be the case, of course, if failure occurred while the force fluctuation was in one of its upward fluctuations. 
When, by applying the external damping, the force fluctuations are fully suppressed the thickness of the silicon grease damping pad shows no notable influence on the maximum load: this gives credit to the identification of the fracture initiation point, and thus on the determination of the critical load, based on force records of this kind.

The thickness of the layer has a marked influence on the time-to-failure: as the thickness is increased the force measured at the load cell increases more gradually and time to fracture increases (Figure 7 left). Shifting the four curves such that the maximum stresses coincide (shown in Figure 7 right) reveals that after the damping material is squeezed out and full contact has been established between the striker and the moving crosshead, the stress versus time curve is no more influenced by the original thickness of the damping layer. Apparently the amount of damping is not critical and a layer of silicon grease of $0.1 \mathrm{~mm}$ thickness appears sufficient to get the desired result on the stress versus time curve and so was used for all other tests conducted during this study.

\subsection{Pendulum speed}

By changing the initial angle of the pendulum impact-testing machine, the speed at which the tensile bar is impacted can be easily varied, be it only over a limited range. Using initial angles of $16^{\circ}, 31^{\circ}$, $63^{\circ}, 103^{\circ}$ and $150^{\circ}$, initial impact speeds of $0.53 \mathrm{~m} / \mathrm{s}, 1.0 \mathrm{~m} / \mathrm{s}, 2.0 \mathrm{~m} / \mathrm{s}, 3.0 \mathrm{~m} / \mathrm{s}$ and $3.7 \mathrm{~m} / \mathrm{s}$, respectively were applied. The speed of the pendulum at impact was verified with the use of a high speed camera. The decrease in speed during impact, both determined by image processing and by integration of the force signal, was found to be well below the $5 \%$ (which is the maximum acceptable deceleration according to the ISO standard [5]) in all cases.

The influence of initial speed of the pendulum on the stress versus time trace of PMMA specimens is shown in Figure 8 (left). With an increase in initial pendulum speed both the time-to-failure and the maximum stress decreases, which is in agreement with the generally accepted observation that the fracture toughness decreases with increasing loading rates. If the stress is plotted against displacement (the almost constant impact speed allows for simple multiplication with initial pendulum speed) as is done in Figure 8 (right), the initial slope of the traces appear to be nearly identical over the range of testing speeds used. This is in accordance with the fact that the rate of displacement is varied less than one decade in a region where the modulus of PMMA does not change drastically.

\subsection{Notch length}

The influence of initial notch length is investigated for all materials by varying it from $1.5 \mathrm{~mm}$ up to $3.5 \mathrm{~mm}$, resulting in notch length/specimen width ratios $(a / w)$ ranging from 0.3 up to 0.7 . The specimens were all tested with an initial pendulum velocity of $1 \mathrm{~m} / \mathrm{s}$. The resulting fracture toughness is plotted against the $a / w$ ratio in Figure 9 . Strikingly, the experimental data show some dependence on the notch length, with fracture toughness apparently decreasing with increasing notch depth over the $a / w$ range explored. This behaviour was observed for all three materials. Using different geometrical functions such as those presented in [26] and [27] did not give significantly different results.

Additional PMMA specimens were tested to extend the range of $a / w$ ratios and check the unexpected influence of the notch length. These tests were carried out at both $1 \mathrm{~m} / \mathrm{s}$ and at 0.1 
$\mathrm{mm} / \mathrm{s}$ (quasi-static) crosshead displacement rate. The resulting fracture toughness values are shown in Figure 10. The results for quasi-static rate (Figure 10, right) are in line with those obtained on the same material in another work using three-point-bending $(\mathrm{SE}(\mathrm{B}))$ tests [28].

The impact results (Figure 10 left) show some kind of parabolic behaviour passing through a maximum with $a / w$ now varying over a wider range. At variance, the quasi-static results (Figure 10, right) do not show this kind of influence. This observation suggests that the influence of the $a / w$ ratio is related to some dynamic effect and/or to the experimental setup, but clearly not to the specimen geometry.

The effect of decreasing the apparent toughness with increasing notch depth could be caused by some spurious bending moments, acting in the specimen plane or in the plane normal to it and to the crack growth direction, as the ones presumed in section 3.1. However, an additional bending moment is expected to reduce the perceived toughness when crack length is increased, as it would reduce the bending stiffness of the specimen. This hypothesis could thus justify only the right-hand side of the curved trend in Figure 10 left. The trend passing through a maximum suggests that there must be another opposite effect prevailing in the short crack length range.

Whether this is again related to some unknown feature of the experimental setup or to the dynamics of the test is something requiring further investigation.

\subsection{Materials comparison}

The influence of test speed was also measured for PVC and PE. The resulting stress versus time traces are shown in Figure 11. A similar behaviour to that of PMMA (Figure 8) was observed: decreasing time-to-failure and decreasing maximum stress with increasing pendulum velocity. The time-tofailure is, however, significantly higher for the PE specimens. Furthermore, for some of the measurements on PVC and PE conducted at an initial pendulum speed of $1 \mathrm{~m} / \mathrm{s}$, the LEFM criteria as prescribed by ISO 13586 [17] (to which ISO 17281 refers in this regard) are not met. This clearly suggests an increase in ductility with decreasing impact rate and displays a lower impact rate boundary for the applicability of the fracture toughness tests based on LEFM to somewhat more ductile materials such as PVC and PE with the investigated geometry. The relevant "invalid" measurements were disregarded from further analysis.

Looking at the fracture surface of the PVC and PE specimens, depicted in Figure 12, it shows that both PVC and PE display a mostly brittle fracture surface near the notches (thus at initiation). The shear lips at the top and bottom centre of the PE specimen show that with the growth of the cracks, plane stress conditions become more and more relevant for PE. As this study only focuses on the fracture initiation, this ductile contribution to the crack growth is of less importance here.

The mode I fracture toughness of the three materials as determined at the various speeds is shown in Figure 13 (left). As already stated, not all tests on PVC and PE at lower impact speeds comply with the data reduction and LEFM conditions as prescribed in ISO 17281 and ISO 13586, respectively. Only the fracture toughness values of the tests that do comply are reported in Figure 13. Three measurements were carried out at each velocity, resulting only in a small scatter in Kıc values. The fracture toughness appears to decrease with increasing pendulum velocity for all three materials. This result is perfectly in line, for the range of speeds investigated, with the results obtained in a 
round-robin performed by members of the Technical Committee 4 of the European Structural Integrity Society (reported in [29]). The results are comparable not only qualitatively, but also quantitatively. In the following discussion section a further comparison with fracture toughness results as measured with different loading geometries (from the literature) is given.

It is worth remarking that, because of the differences in time-dependent modulus in polymers, it makes a difference whether their rate-dependent behaviour is compared under conditions of same loading rate (or stress intensity rate here), or load-point displacement rate (i.e. pendulum velocity here) or time (time-to-fracture here). To illustrate this effect, the fracture toughness of the materials under investigation is plotted against the corresponding time-to-fracture initiation in Figure 13 (right). When comparing the materials this way, PE shows lower fracture toughness for comparable failure times, whereas PMMA and PVC hardly differ. For all materials the fracture toughness increases with failure time, in line, at least for the range of test speeds investigated here, with the results reported in [29].

\section{Discussion}

The relatively large distance the stress wave has to travel from the crack section to the load cell raises the question whether the force measured by the load cell is a sufficiently close approximation of the force acting at the crack section. The outcome of the experiment with sets of two double notches indicates that the force is rather constant along the specimen, as it would be in the case of a quasi-static test, at least up to the half distance from the specimen mid-cross-section to the fixed cross-head (where the load cell is). This is considered a good indication that the force measured at the load cell location is close to the one acting in the specimen and thus the data analysis scheme as set out by ISO 17281 [5] should apply to the test.

A more stringent verification, obtained from an experiment with the second pair of notches placed closer to the load cell, was not attempted because edge effects could have come into play.

The result of $K_{I C}$ apparently depending on the $a / w$ ratio (Fig. 9 and 10 left) is rather disturbing. The fact that the dependence is shown by all materials tested, which were of different thicknesses, makes us think that this result is not related to bending moments acting across the specimen width, which would be caused by a misalignment of the upper and lower parts of the movable crosshead (see Fig. 2). Rather, they could be related to bending moments acting across the specimen thickness, which could arise due to a rotation of the movable crosshead around the specimen thickness direction, resulting in the hammer hitting one crosshead side before the other. There is, however, evidence [30] that a misalignment of that kind would result in a typical shape of the load trace with a low initial stiffness followed by a relatively long plateau before the final load increase leading to fracture: nothing like that was observed here. Furthermore, if such a misalignment was present, fracture would not be expected to initiate at both crack tips of the $D E(T)$ specimens as was observed and described in 3.3. Further studies are therefore required to find out the actual physical background of the observed dependency.

Notwithstanding the two issues above, instrumented tensile impact testing does seem to be a valuable technique to determine the fracture toughness of polymers at relatively high loading rates, namely higher than the conventional testing speed of $1 \mathrm{~m} / \mathrm{s}$ covered by ISO 17281 . As a matter of 
fact even under the highest testing speed conditions used here $(3.7 \mathrm{~m} / \mathrm{s})$ fracture toughness can be directly determined from the recorded force signal.

Results obtained in this study are comparable with results obtained using different methods and different loading configurations. An example is displayed in Figure 14 where literature data on PVC from Major \& Lang [16] are reproduced. They include data at impact speeds higher than $1 \mathrm{~m} / \mathrm{s}$, determined by the DKC method [11-13]. Both the values and the slope of the fracture toughness vs. loading rate agree within a reasonable experimental scatter.

It is noteworthy that while for the measurements on the bending configurations other methods such as the DKC method had to be employed at the higher rates, because the load traces were unusable from above $1 \mathrm{~m} / \mathrm{s}$ [29, 31], the force measurements from tensile impact tests can still be analysed with the same scheme set out in ISO 17281, at least up to $3.7 \mathrm{~m} / \mathrm{s}$ (the maximum speed that could be explored in this study using a standard pendulum impact-testing machine). It remains to be explored if this limit can be increased further since the oscillations in the load signal are still rather contained at $3.7 \mathrm{~m} / \mathrm{s}$. With reference to the verification part of the data reduction procedure (section 2.3) prescribed in ISO 17281, it is to be observed that the oscillations fell not just in the $\pm 5 \%$ envelope (i.e. between the two curves given by $\left.F(t) \pm 0.05 F_{Q}\right)$, but within a narrower $\pm 2 \%$ envelope up to $2 \mathrm{~m} / \mathrm{s}$ and within roughly a $\pm 3 \%$ envelope at $3.7 \mathrm{~m} / \mathrm{s}$. Without further experiments or the use of a predictive model of the test it would of course be hypothetical to forecast how much further the speed could be raised, but some possibility exists.

In addition to fracture toughness expressed in terms of the critical stress intensity factor, $K_{c}$ (linear elastic) fracture mechanics testing methods often consider the determination of fracture toughness in terms of the critical energy release rate, $G_{c}$, in an independent way, i.e. not from $K_{c}$ and the modulus $E$ via the relationship $G=K^{2} / E$. That is generally carried out through methods involving the measurement of the energy up to fracture via integration of the load-displacement curve. This is the case of ISO 17281 [5], ISO 13586 [17] and ASTM D 5045 [32]. In the cited standards the method is a multi-specimen one, prescribing to test specimens differing in the $a / w$ ratio and to get $G_{c}$ from the slope of an energy vs. $a / w$ plot.

Generally, corrections for the compliance of the measuring system and other spurious energy contributions need to be applied if the displacements are not directly measured with an external device (optical for instance). The above referenced standards describe a calibration technique meant to take into account indentation of the loading pins (on $\mathrm{SE}(\mathrm{B})$ and $\mathrm{C}(\mathrm{T})$ specimens) and machine and damper compliance; the calibration procedure involves tests to be run on un-cracked samples.

For the tensile impact setup considered herein a direct measurement of the movable clamp displacement is impractical, as the C-shaped striker hides both the specimen and the moving crosshead, during the test. On the other hand a procedure for the compliance calibration of the testing system for such a setup has not yet been devised. An effective calibration procedure should also take into account the possible indentation of the screw tightening the specimen at the fixed crosshead and, at the same time, it should be performed on a specimen of negligible tensile compliance (e.g. as short as possible) with respect to the compliance of the measuring system. This is left as a refinement for future work.

\section{Conclusions}


The goal of the research presented was to assess whether instrumented tensile impact testing is a robust method to determine the fracture toughness of polymers at rates around and above $1 \mathrm{~m} / \mathrm{s}$, which is the conventional 'moderately high rate' covered by ISO 17281, using the extension of the quasi-static data-analysis scheme proposed therein. The results are very promising as measurements on multiple specimens have nearly identical force-time traces and the dynamic effects prove to be less critical even at higher test speeds than for bending geometries. Consequently the fracture toughness can be determined directly from the recorded load, even for the highest impact speeds tested here $(3.7 \mathrm{~m} / \mathrm{s})$ and by applying only limited damping. The resulting toughness values are comparable with those found in literature and measured using different methods (e.g. via time-tofracture and DKCs) or other loading configurations.

Further research work is needed, however, to clarify the possible occurrence of bending during tensile impact testing and to explain the observed influence of the notch length on the fracture toughness determination. Finite element simulations, even in a static framework, may provide indications on how much the bending moment is contributing to, or modifying, the stress intensity factor at varying crack length. A similar study on a different geometry, namely the single edge notch tensile $(\mathrm{SE}(\mathrm{T}))$, with a very different bending stiffness, may prove useful in identifying the cause of the observed dependence of $K_{I C}$ on $a / w$.

Larger pendulums or drop tower instruments using a tensile impact fixture are necessary to assess the applicability and the robustness of this test method up to even higher test speeds than tested in this work $(3.7 \mathrm{~m} / \mathrm{s})$ : at present the upper speed limit cannot be predicted.

\section{Acknowledgements}

This work follows an exploratory MSc thesis work carried out in the same laboratory previously [28]. Several issues broached here were hinted from findings rising out of that work. Francesco Caimmi gratefully acknowledges partial support by Italy's Consorzio Interuniversitario Nazionale per la Scienza e la Tecnologia dei Materiali (INSTM) through grant ID/DB234. The authors wish to thank Mr Oscar Bressan for assistance in the experiments.

\section{References}

[1] Cotterell, B. (1962). Fracture toughness and the Charpy V-notch impact test. British Welding Journal, 9, 83-89

[2] Radon, J., \& Turner, C. (1969). Fracture toughness measurements by instrumented impact test. Engineering Fracture Mechanics, 1(3), 411-428. (doi:10.1016/0013-7944(69)90002-2)

[3] Pavan, A., \& Williams, J. G. (2000). Development of a Standard for Determining $K_{I C}$ and $G_{I C}$ for Plastics at High Loading Rates: the ESIS Protocol for $1 \mathrm{~m} / \mathrm{s}$ Testing. In J. S. Peraro (Ed.), Limitations of Test Methods for Plastics, ASTM STP 1369 (pp.130-145). ASTM, West Conshohocken, PA, USA 
[4] Pavan, A. (2001). Determination of Fracture Toughness $\left(G_{I C}\right.$ and $\left.K_{I C}\right)$ at Moderately High Loading Rates. In D. R. Moore, J. G. Williams \& A. Pavan (Eds.), Fracture Mechanics Testing Methods for Polymers, Adhesives and Composites, ESIS 28 (pp. 27-58). Elsevier, Amsterdam

[5] ISO 17281:2002(E), Plastics - Determination of fracture toughness $\left(G_{I C}\right.$ and $\left.K_{I C}\right)$ at moderately high loading rates $(1 \mathrm{~m} / \mathrm{s})$, ISO, 2002

[6] Grellmann, W., \& Reincke, K. (2007). Procedure for determining the crack resistance behaviour using the instrumented notched tensile-impact test. (pp. 1-8). Mechanische Prüfung von Kunststoffen, retrieved from: http://polymer.joppnet2.biz/fileadmin/sachverstaendigenbuero/pdfs/p e.pdf

[7] Venzi, S., Priest, A.H. \& May, M.J. (1970). Influence of Inertial Load in Instrumented Impact Tests. Impact Testing of Metals, ASTM STP 466 (pp. 165-180). ASTM, Philadelphia, USA.

[8] Kalthoff, J. F. (1985). On the measurement of dynamic fracture toughnesses - a review of recent work. International Journal of Fracture, 27(3-4), 277-298. Springer Netherlands. (doi:10.1007/BF00017973)

[9] Williams, J. G., \& Adams, G. C. (1987). The analysis of instrumented impact tests using a mass-spring model. International Journal of Fracture, 33(3), 209-222. (doi:10.1007/BF00013171)

[10]Pavan, A., \& Draghi, S. (2000). Further experimental analysis of the dynamic effects occurring in three-point bending fracture testing at moderately high loading rates $(1 \mathrm{~m} / \mathrm{s})$ and their simulation using an ad hoc mass-spring-dashpot model. In J. G. Williams \& A. Pavan (Eds.), Fracture of Polymers, Composites and Adhesives, ESIS 27 (pp. pp. 347-361). Elsevier, Amsterdam (doi:10.1016/S1566-1369(00)80030-8)

[11]Kolsky, H. (1949). An Investigation of the Mechanical Properties of Materials at Very High Rates of Strain, Proc. Roy. Phys. Soc., B 62, 676-700

[12]Kinloch, A. J., Kodokian, G. A., \& Jamarani, M. B. (1987). Impact properties of epoxy polymers. Journal of materials science, 22(11), 4111-4120. Springer. (doi:10.1080/10934528709375375)

[13]Böhme, W. (1990). Dynamic key-curves for brittle fracture impact tests and establishment of a transition time. In J. P. Gudas, J. A. Joyce, \& E. M. Hackett (Eds.), Fracture Mechanics: Twenty-First Symposium (pp. 144-156). ASTM, Philadelphia, USA.

[14]Böhme, W. (1995). Application of dynamic key curves for the determination of the impact fracture toughness of polymers at high rates of loading. In J. G. Williams \& A. Pavan (Eds.), Impact and Dynamic Fracture of Polymers and Composites, ESIS 19 (pp. 59-71). MEP, London.

[15]Williams, J. G., Braga, L. M. \& MacGillivray, H. J. (1995). The measurement of fracture toughness via time-to-fracture for impact testing of polymers. In J. G. Williams \& A. Pavan (Eds.), Impact and Dynamic Fracture of Polymers and Composites, ESIS 19 (pp. 45-57). MEP, London. 
[16]Major, Z., \& Lang, R. (2003). Rate dependent fracture toughness of plastics. In B. R. K. Blackman, A. Pavan, \& J. G. Williams (Eds.), Fracture of Polymers, Composites and Adhesives II (Vol. 32, pp. 187-198). Elsevier Ltd. And ESIS. (doi:10.1016/S1566-1369(03)80094-8)

[17]ISO 13586:2000/Amd.I:2003(E), Plastics - Determination of fracture toughness ( $G_{I C}$ and $K_{I C}$ )Linear elastic fracture mechanics (LEFM) approach, ISO, 2003

[18]Rooke, D. P., \& Cartwright, D. J. (1976). Compendium of Stress Intensity Factors. London: Her Majesty's Stationery Office.

[19]Green, A. K., \& Pratt, P. L. (1974). Measurement of the dynamic fracture toughness of polymethylmethacrylate by high-speed photography. Engineering Fracture Mechanics, 6(1), 71-80. (doi:10.1016/0013-7944(74)90047-2)

[20]Hitoshi, W. (1992). Determination of dynamic fracture toughness for PMMA. Engineering Fracture Mechanics, 41(6), 821-831. (doi:10.1016/0013-7944(92)90234-6)

[21]Maigre, H., \& Rittel, D. (1993). Mixed-mode quantification for dynamic fracture initiation: Application to the compact compression specimen. International Journal of Solids and Structures, 30(23), 3233-3244. (doi:10.1016/0020-7683(93)90111-J)

[22] Costa, J. D. M., Capela, C., \& Ferreira, J. A. M. (2011). Mechanical behaviour of PVC/CaCO3 Particulate Composites - Influence of Temperature. Strain, 47, e292-e304. (doi:10.1111/j.1475-1305.2009.00624.x)

[23]Ravi-Chandar, K. (2004). Dynamic fracture (First.). Oxford: Elsevier Ltd.

[24]Kirugulige, M. S., Tippur, H. V., \& Denney, T. S. (2007). Measurement of transient deformations using digital image correlation method and high-speed photography: application to dynamic fracture. Applied Optics, 46(22), 5083. OSA. (doi:10.1364/AO.46.005083)

[25]Cotterell, B. (1968). Fracture propagation in organic glasses. International Journal of Fracture Mechanics, 4(3), 209-217. Springer Netherlands. (doi:10.1007/BF00185257)

[26]Brown, H. F., \& Srawley, J. E. (1966). Plane Strain Crack Toughness Testing of High Strength Metallic Materials. ASTM STP410. (doi:10.1520/STP410-EB)

[27]Murakami, Y. (1987). Stress Intensity Factors Handbook. Pergamon Press, Oxford

[28]Caimmi, F. (2009). Short fibre polymer composites: crack/fibre interaction in a single fibre model material. PhD diss., Politecnico di Milano, Milano.

[29]Rager, A. (2003). Analysis of high rate fracture tests of polymers. PhD diss., Imperial College London.

[30]Ghezzi, M. (2003). Analisi sperimentale e modellazione della prova di frattura per impatto a trazione su materiali polimerici. MSc thesis, Politecnico di Milano, Milano. 
[31]Adams, G. C., Bender R. G., Crouch B. A. \& Williams, J. G. (1990). Impact fracture toughness tests on polymers. Polymer Engineering \& Science, 30, 241-248.

[32]ASTMD 5045-99, Standard test methods for plane-strain fracture toughness and strain energy release rate of plastic materials, ASTM International, June 1999 
Figures

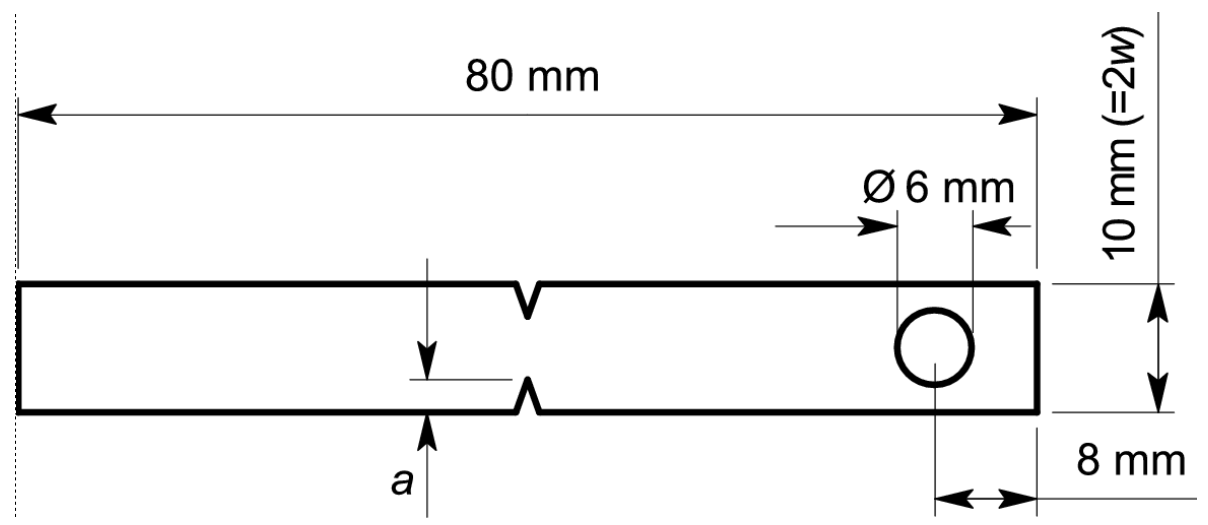

Figure 1 Geometry of the tensile impact specimen, with $a$ as the notch length $(2.5 \mathrm{~mm}$ in all cases, unless stated otherwise).

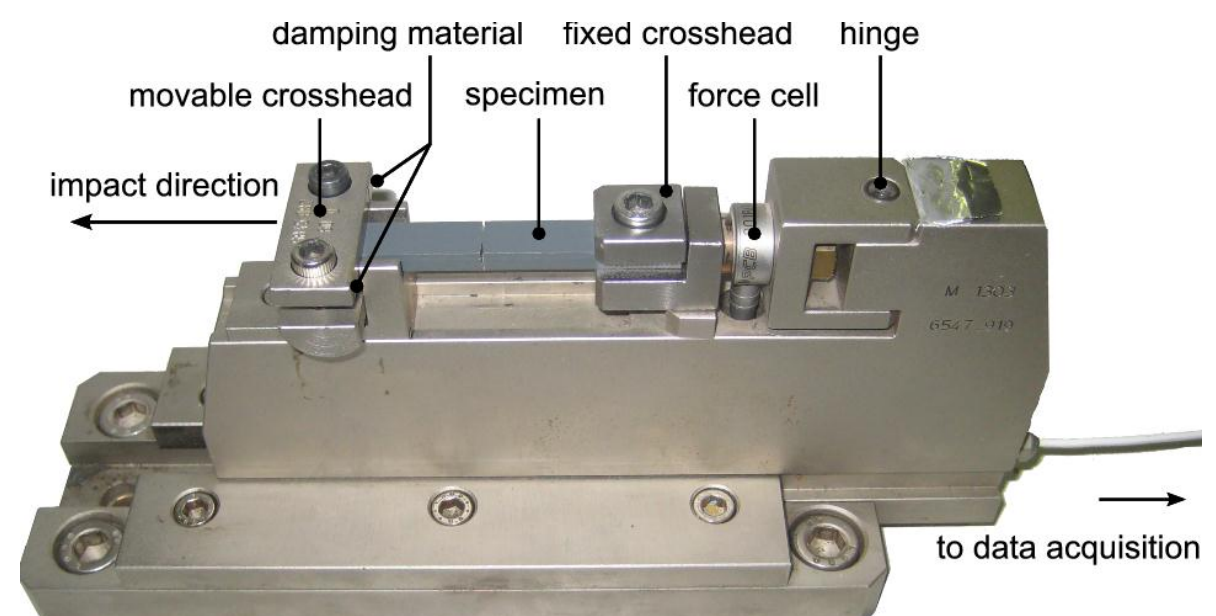

Figure 2 Photograph of the experimental setup used for the tensile impact tests.
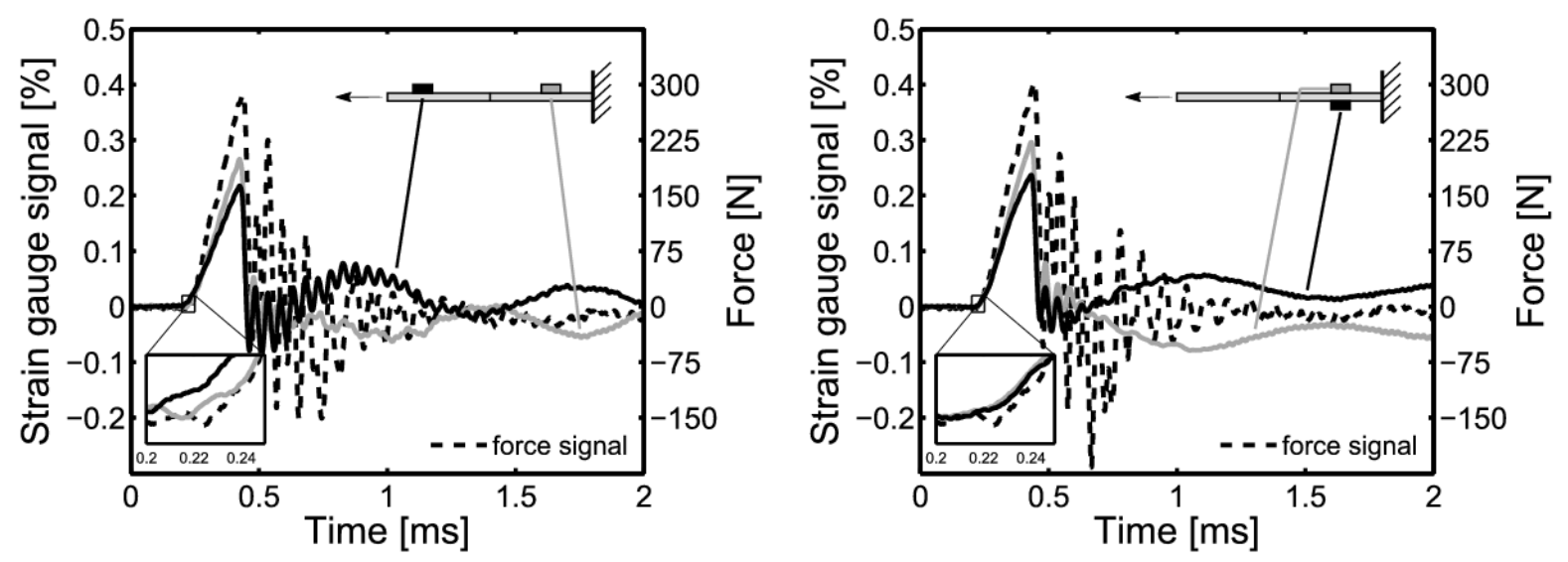

Figure 3 Strain gauge and force cell signals of tensile impact tests on PMMA specimens equipped with two strain gauges in two different configurations: one upstream and downstream (left) and downstream on the top and bottom of the specimen (right). The tests were carried out at an initial pendulum velocity of $1 \mathrm{~m} / \mathrm{s}$ with $0.1 \mathrm{~mm}$ thick silicon grease damping pads. 


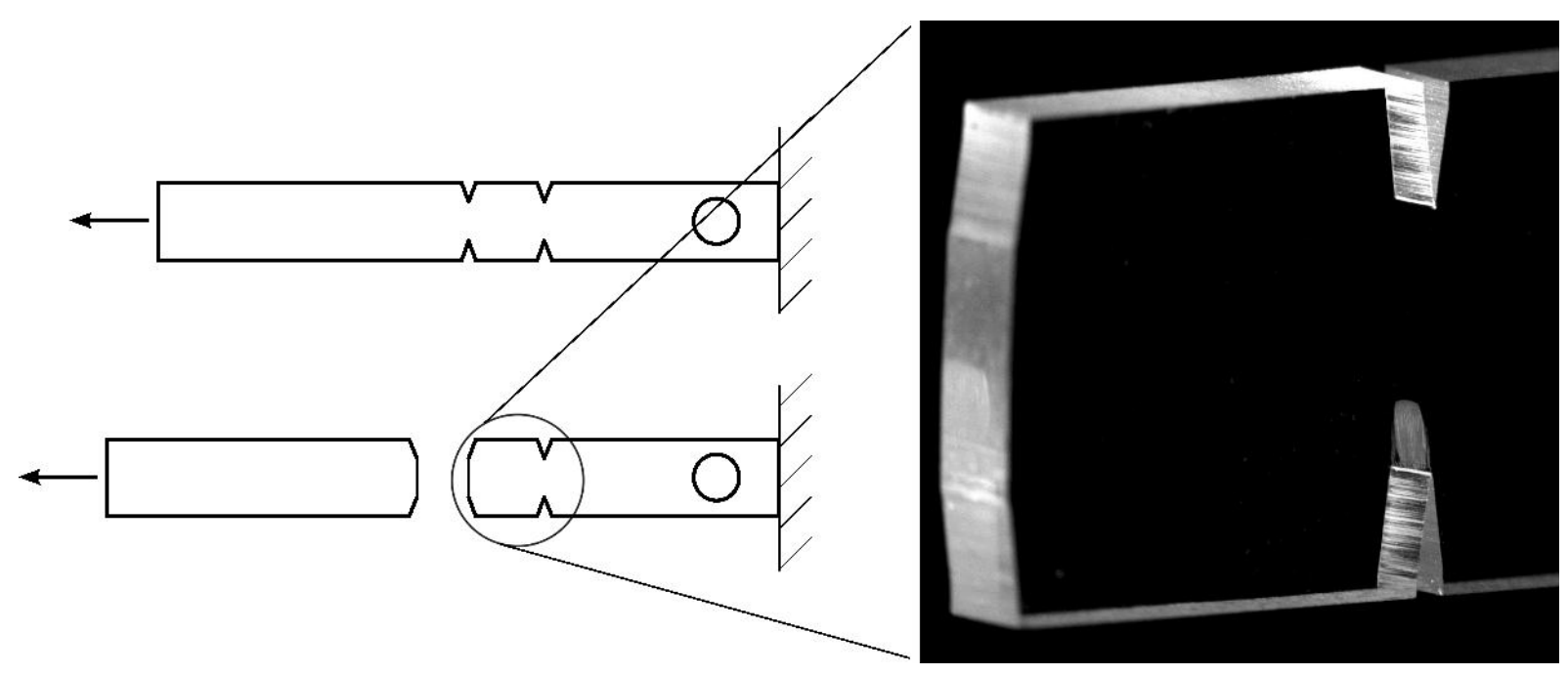

Figure 4 Schematic representation of specimens with a double pair of notches and a photograph of the second pair of notches in a PMMA specimen after test (at $1 \mathrm{~m} / \mathrm{s}$ ).

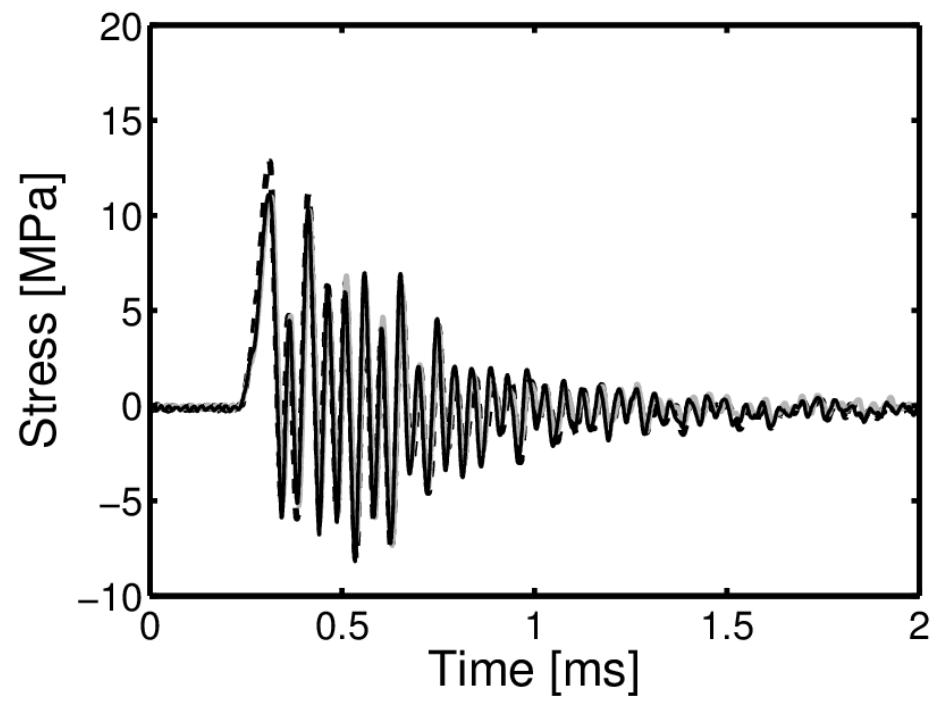

Figure 5 Stress signal versus time for three PMMA specimens tested at $1 \mathrm{~m} / \mathrm{s}$ with $0.1 \mathrm{~mm}$ thick silicon grease damping pads. 


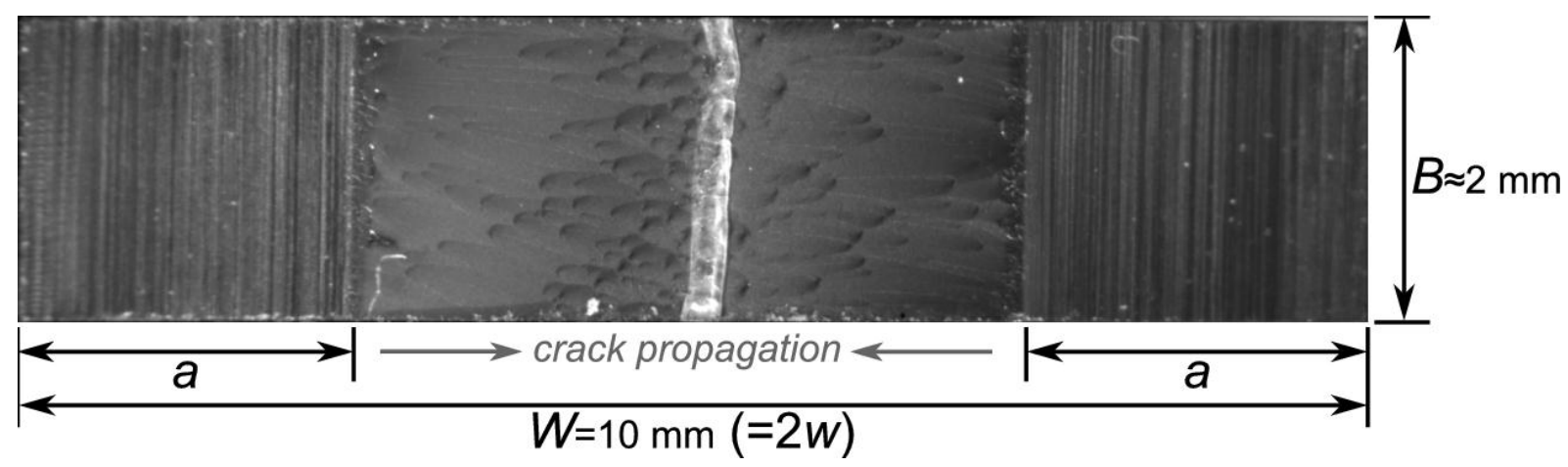

Figure 6 Fracture surface of a PMMA specimen tested at $1 \mathrm{~m} / \mathrm{s}$.
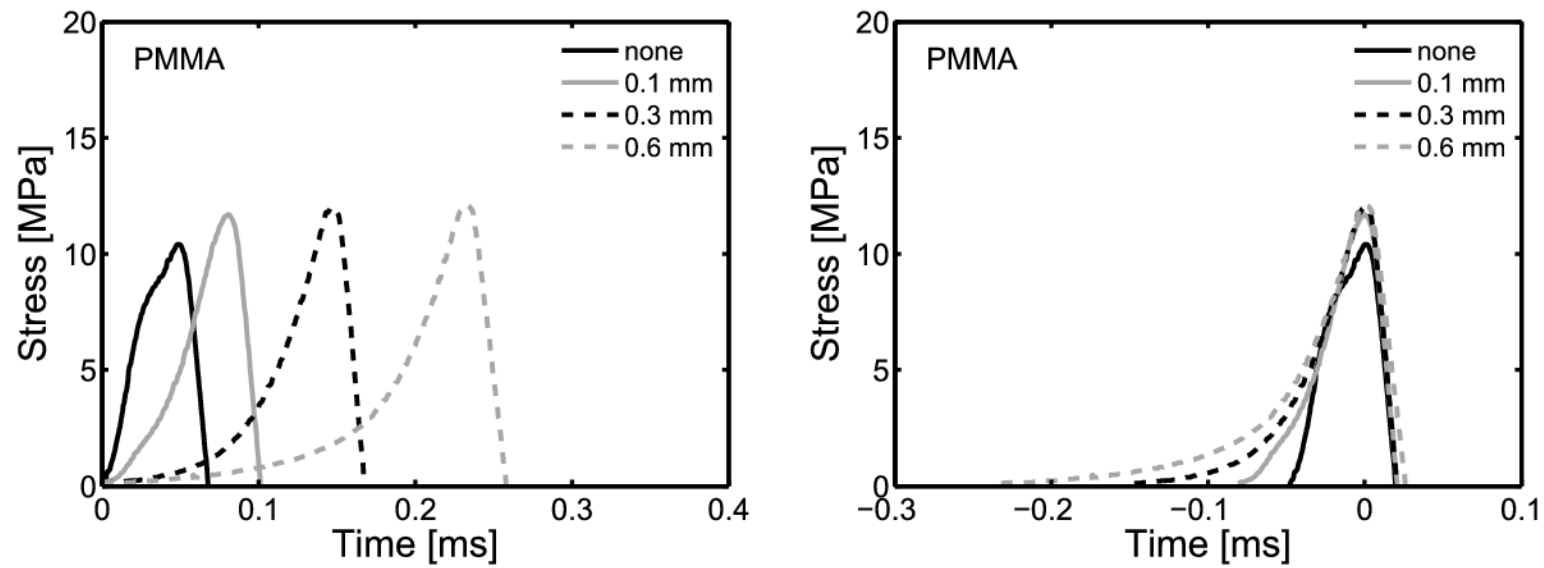

Figure 7 Stress signal for PMMA specimens tested at $3.7 \mathrm{~m} / \mathrm{s}$ with silicon grease damping pads of different thicknesses, as indicated in the inset. Time axis with the origin at the start of the test (left) and at the time of maximum stress (right) for the sake of comparison.
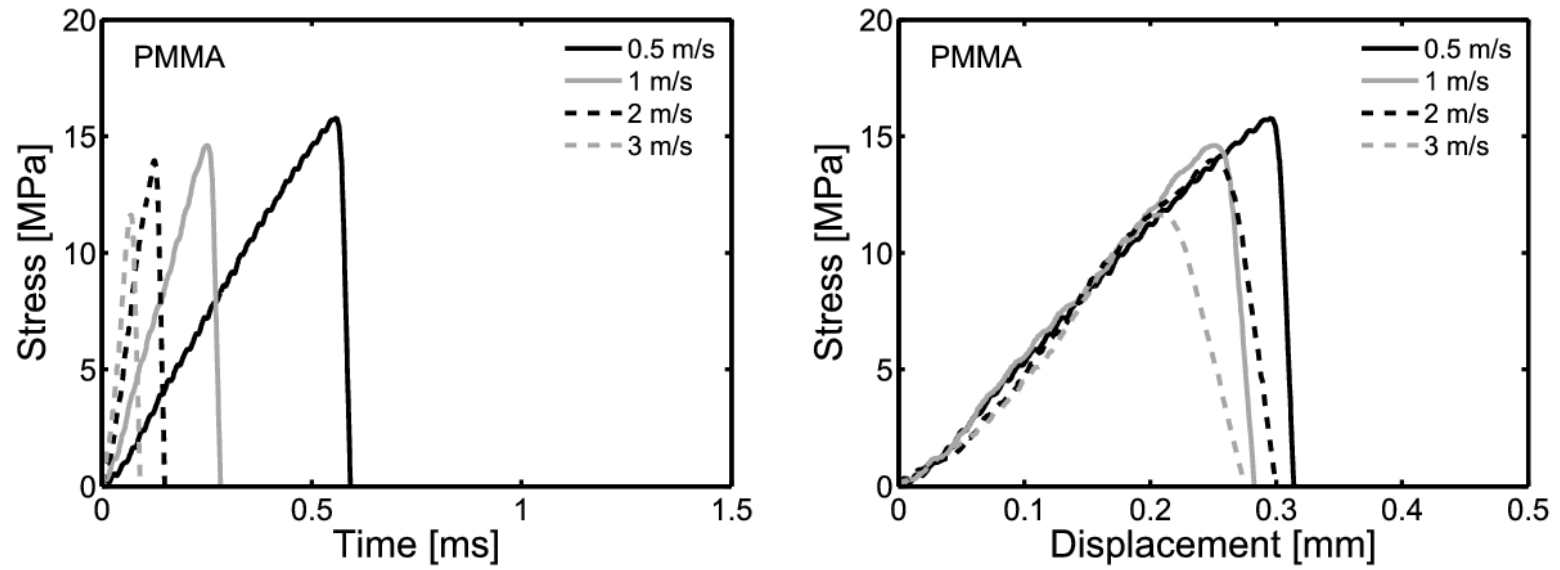

Figure 8 Stress versus time (left) and versus displacement (right) for PMMA specimens tested at different initial pendulum velocities, using $0.1 \mathrm{~mm}$ thick silicon grease damping pads. 


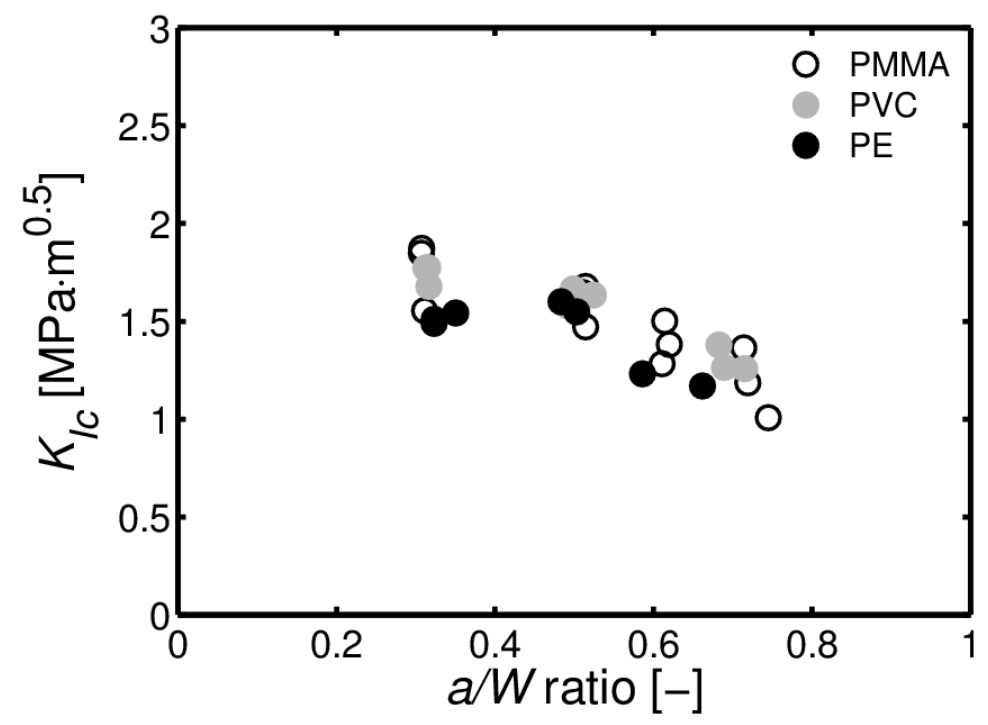

Figure 9 Fracture toughness as measured at $1 \mathrm{~m} / \mathrm{s}$ using PMMA, PVC and PE specimens with different initial notch lengths $(a)$.
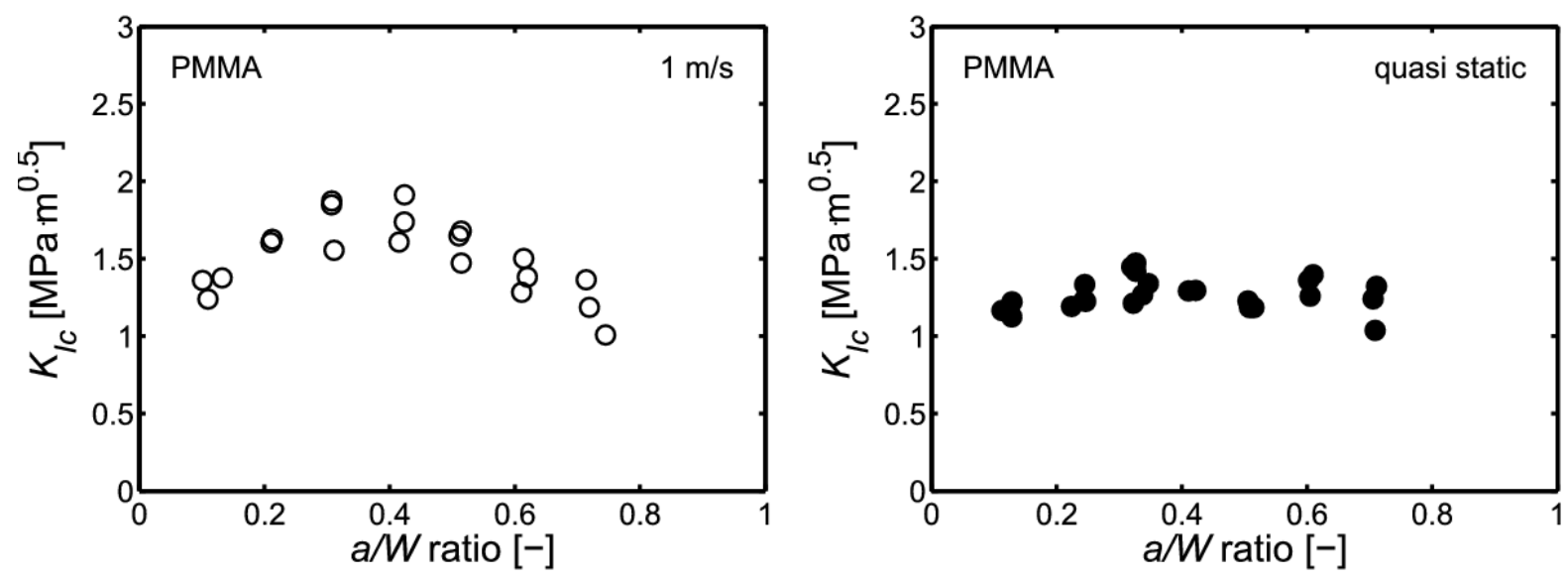

Figure 10 Fracture toughness of PMMA specimens with different initial notch lengths $(a)$ as measured at $1 \mathrm{~m} / \mathrm{s}$ (left) and at a quasi-static velocity of $0.1 \mathrm{~mm} / \mathrm{s}$ (right).
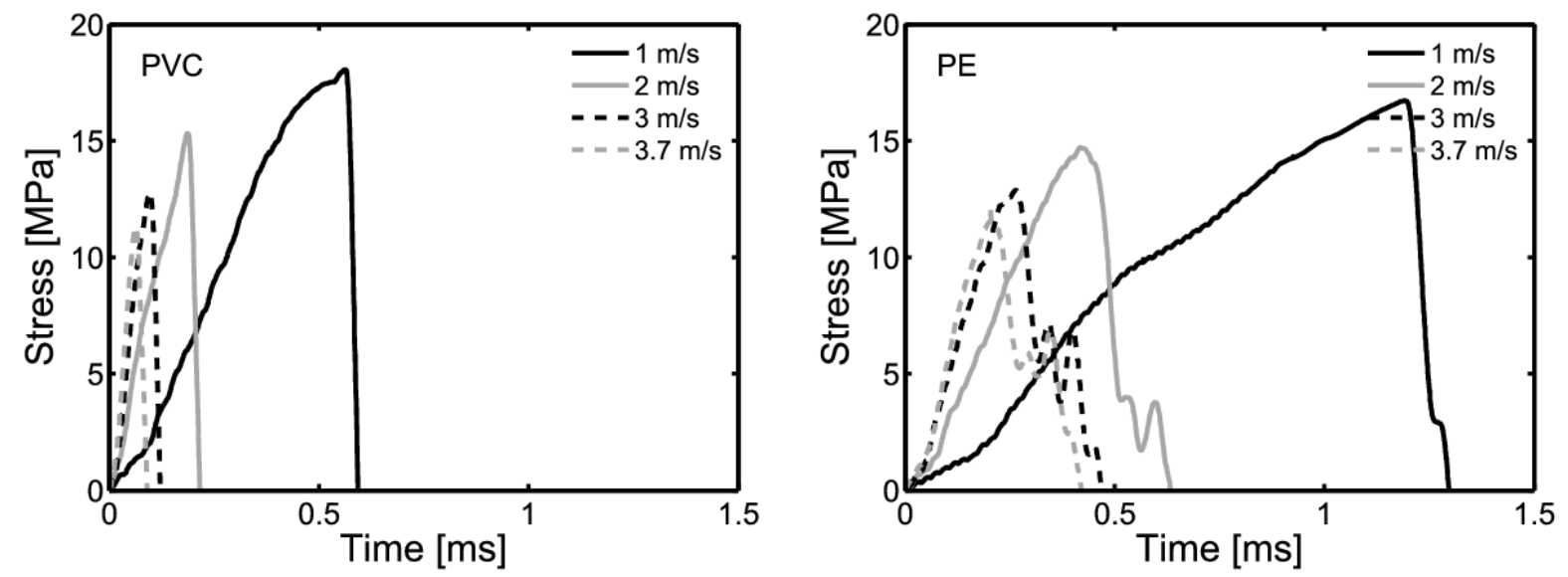

Figure 11 Stress versus time for PVC (left) and PE (right) specimens tested at different initial pendulum velocities, using $0.1 \mathrm{~mm}$ thick silicon grease damping pads. 

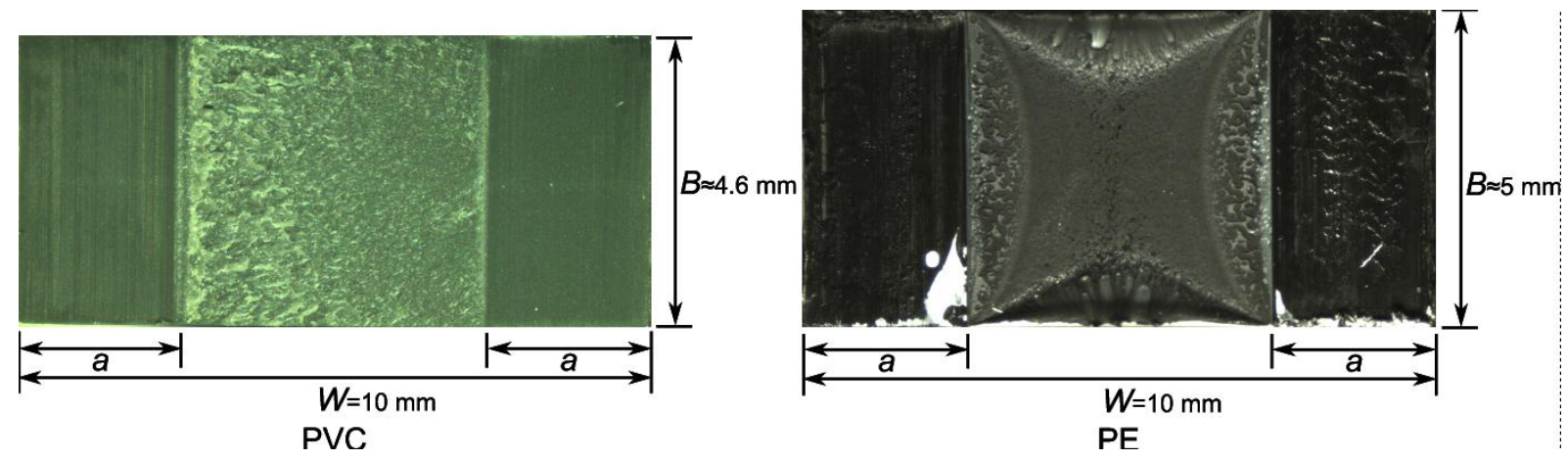

Figure 12 Fracture surface of a PVC (left) and a PE (right) specimen after testing at $1 \mathrm{~m} / \mathrm{s}$.
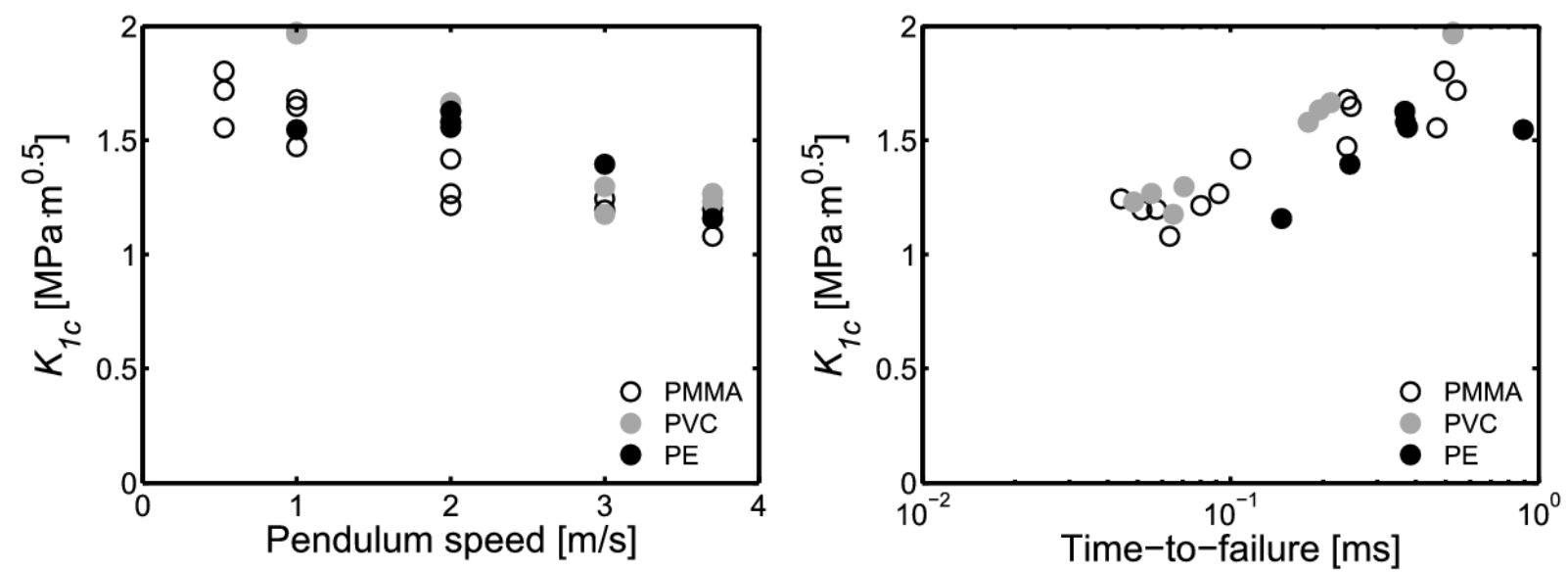

Figure 13 Fracture toughness versus initial pendulum velocity (left) and versus time-to-failure (right) for PMMA, PVC and PE.

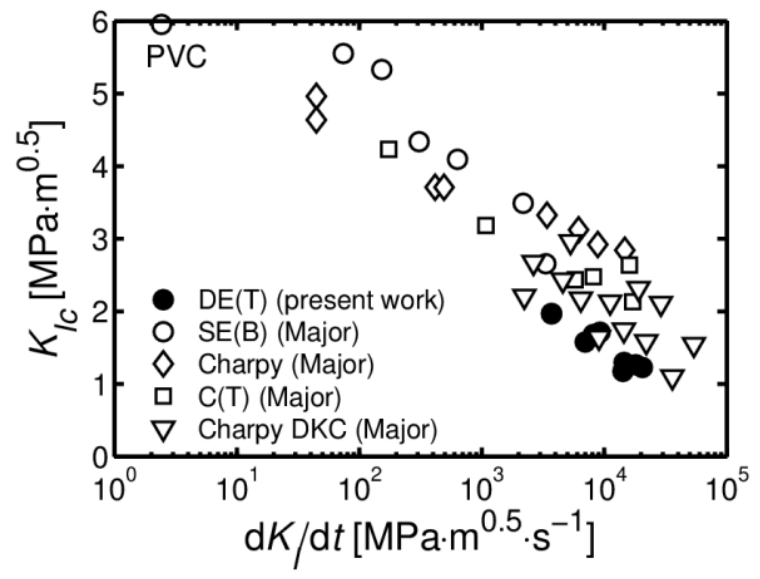

Figure 14 Fracture toughness versus loading rate (expressed as stress intensity factor rate) for PVC. The results determined in this study (full circles) are compared with results obtained by Major \& Lang with different methods and geometries [14, figure 11]. $S E(B)$ means standard fracture mechanics three-point-bending specimens. "Charpy" means SE(B) specimens with Charpy dimensions. "Charpy DKC" means measurements on $\mathrm{SE}(\mathrm{B})$ specimens with Charpy dimensions analysed with the DKC method, because of the higher impact rates. (Note: Only the low rate data below $K_{I C}=6 \mathrm{MPa} \cdot \mathrm{m}^{1 / 2}$ are shown here. According to [14] their data for $\mathrm{d} K / / \mathrm{d} t<4 \cdot 10^{2} \mathrm{MPa} \cdot \mathrm{m}^{1 / 2} \cdot \mathrm{s}^{-1}$ circa do not qualify as admissible according to standard LEFM criteria) 